\title{
Discovering the campus together: a mobile and computer-based learning experience
}

Mar Pérez-Sanagustín ${ }^{1 *}$, Gustavo Ramirez-Gonzalez ${ }^{2,3}$, Davinia Hernández-Leo ${ }^{1}$, Mario MuñozOrganero $^{2}$, Patricia Santos ${ }^{1}$, Josep Blat ${ }^{1}$ and Carlos Delgado Kloos ${ }^{2}$

${ }^{1}$ Universitat Pompeu Fabra, Roc Boronat 13808018 Barcelona, SPAIN (e-mail: \{mar.perez@, davinia.hernandez@,patricia.santos@,josep.blat@\}upf.edu).

${ }^{2}$ Universidad Carlos III de Madrid, Av. Universidad, 30, 28911 Leganés (Madrid), SPAIN (email: \{gramirez, munozm, cdk\}@it.uc3m.es).

${ }^{3}$ Universidad del Cauca, Campus Tulcán, Popayán, COLOMBIA (e-mail: gramirez@unicauca.edu.co).

*Corresponding autor: Mar Pérez-Sanagustín (mar.perez@upf.edu,mdelmar.ps@gmail.com) 
Abstract One of the most relevant difficulties faced by first-year undergraduate students is to settle into the educational environment of universities. This paper presents a case study that proposes a computer-assisted collaborative experience designed to help students in their transition from high school to university. This is done by facilitating their first contact with the campus and its services, the university community, methodologies and activities. The experience combines individual and collaborative activities, conducted in and out of the classroom, structured following the Jigsaw Collaborative Learning Flow Pattern. A specific environment including portable technologies with network and computer applications has been developed to support and facilitate the orchestration of a flow of learning activities into a single integrated learning setting. The result is a Computer-Supported Collaborative Blended Learning scenario, which has been evaluated with first-year university students of the degrees of Software and Audiovisual Engineering within the subject Introduction to Information and Communications Technologies. The findings reveal that the scenario improves significantly students' interest in their studies and their understanding about the campus and services provided. The environment is also an innovative approach to successfully support the heterogeneous activities conducted by both teachers and students during the scenario. This paper introduces the goals and context of the case study, describes how the technology was employed to conduct the learning scenario, the evaluation methods and the main results of the experience.

Keywords Collaborative Learning and Applications; Computer Supported Collaborative Blended Learning; Collaborative Learning Flow Pattern; Mobile and ubiquitous computing; NFC; Innovative Collaborative Scenarios

\section{Introduction}

One of the aspects that make first year students drop out or persist in engineering majors is the way they face the transition from high school to university. Psychological studies discuss the 
importance of emotional and social competence during this transition (Parker et al, 2004). West (1991) claims that the more integrated students are in the social activities of a campus environment; the more likely they are to success in their studies at university.

In addition to the difficulties due to the development of effective emotional and social competencies to settle into their new lives, students must overcome practical problems brought about by the academic environment, such as locating lecture rooms, the secretary and using the services provided by libraries in the campus. When arriving at their university for the first time, most of the first-year students do not know either the services or resources offered by the institution. Nor do they know how to exploit these services until the end of their studies (Anderson-Rowland et al, 2004).

In Spain, this situation is compounded by the European Higher Education Area (EHEA, 2010), which was introduced in universities, including Polytechnics, in 2008. The EHEA system is competence oriented. Learning strategies beyond the traditional ones (e.g. studying the syllabus of subjects) are introduced in order to develop the specific and transversal skills that are necessary to become a good professional. One of the strongest points included in the engineering curriculum is the development of collaborative work skills, as engineers are professionals who work in groups and collaborate for developing large projects (Martínez-Monés et al, 2005). Thus, learning how to interact with colleagues is essential for students of engineering to develop their future career.

First-year engineering students often show motivational problems during the first year. Experts consider that the main reason for this is their poor knowledge of their future professional world, and highlight the need of bringing students closer to practicing engineers. As stated in Haag and Collofello (2008): "To shed a positive light on engineering, advisors, faculty, and teaching 
assistants can show applications of the coursework so the students can connect what they are studying to the "real world".

New approaches are needed to help first-year students to deal with these difficulties and facilitate their transition to university in the three aspects mentioned: (1) introducing them to the campus and services, (2) making them familiar with the EHEA methodologies and collaborative work skills, and (3) fostering their interest in technology and their future career. Different studies have developed technological solutions that address partially these three issues. Sticklen et al (2009) propose replacing lecture sessions with web-based, voice-over slide presentations punctuated with full screen demonstrations and interactive quizzes to improve students' attitude towards engineering. Mueller (2004) discusses an e-mentoring system to connect students to practicing engineers or scientists that increases students' confidence in succeeding in their studies and their wish to pursue their career. Courter \& Anderson (2009) propose including interviews with practicing engineers as part of the first-year student curriculum and show how this improves students' motivation and understanding of engineering practice.

We consider that explaining the services available at university and the information that can be found on the web is not enough for a first and effective contact with the new learning environment (campus, community members and activities). It is also necessary to facilitate and support students' first-hand experiences with the services distributed around the campus to foster their motivation and interest in the new environment. The potential of mobile and interactive technologies to improve communication among students and provide more contextualized learning experiences in different spaces beyond the classroom has attracted considerably research (Cook et al, 2006; Cook et al, 2008; Roschelle \& Pea, 2002). Projects such as Savannah (Facer et al, 2004), MyArtSpace (Sharples et al, 2007) or the work by Schwabe \& Goth (2005) show that interactive experiences involving an active exploration of the environment improve students' 
motivation. Thus, we propose a learning setting that: (1) integrates activities in the classroom and around the campus, (2) involves students as a way of increasing their motivation and (3) helps them to discover the campus, their new classmates and university methodologies.

To meet these needs in an integrated manner, this paper presents a case study of an innovative Computer Supported Collaborative Blended Learning (CSCBL) scenario, which was carried out with first-year engineering students at Pompeu Fabra University (Barcelona, Spain). The scenario is structured according to the Jigsaw Collaborative Learning Flow Pattern (CLFP). A CLFP aims at capturing the essence of well-known techniques for structuring a flow of learning activities to potentially produce effective learning from collaborative situations (Hernández-Leo et al, 2005). With this CLFP we intend: (1) to foster collaboration amongst students so they can meet each other and (2) to integrate the set of activities into a coherent flow of learning activities. We encourage the active participation of the students and facilitate their first contact with the environment through a set of formal and informal activities, which take place in different areas of the campus. We developed a technological environment combining different network and computer applications to ensure the integration of all these activities and ease their orchestration. The experience consists of three phases. The first one takes advantage of mobile phones and NFC/RFID (Near Field Communication/ Radio Frequency Identification) technologies to support an exploratory informal activity around the campus; in the second phase, the students use computers to work collaboratively on a formal presentation about their exploration of the campus, and, the third phase, is an online Web questionnaire for students to reflect about the whole experience.

This case study illustrates the suitability of generating innovative blended scenarios combining formal and informal activities conducted in different spatial locations with significant learning benefits. We seek to stress the value of conducting this type of CSCBL experiences to both 
enhance students' motivation towards technology and introduce them to the services which are of benefit for them to carry out their studies. Moreover, we show how technologies and collaborative learning techniques complement each other in generating innovative collaborative computing experiences which facilitate effective learning

Next section introduces the educational context in which the case study was carried out and defines its main requirements. The implementation of the CSCBL scenario and the supporting technological environment developed are detailed next. The following section summarizes the evaluation of the case study by presenting the evaluation objectives, methodology and main findings. Finally, the main conclusions and a discussion of future research lines are presented.

\section{Description of the case study, context, and CSCBL scenario}

\subsection{Educational context}

The case study was conducted within the framework of Information and Communication Technologies Introduction (ICTI), a compulsory subject for first-year students of three ICT engineering degrees (Computing, Telematics and Audiovisual Systems) offered in the new curriculum of Pompeu Fabra University (UPF). The subject aims at giving a global vision of UPF and its resources. The subject is also an introduction to the professional ICT world and includes an activity to introduce students to the campus and its services.

The new curriculum includes methodologies which make use of technology to support group work and the development of oral and written communication competences. UPF uses Moodle (Dougiamas et al, accessed 2010; Moodle 2010) as the platform to manage the content and communication needs. This case study promotes the aforementioned skills through a collaborative learning scenario, which is based on the Jigsaw CLFP (explained later) being applied to a blended learning context. The activity is designed to help students become familiar 
with the campus, learn about the services offered and meet other classmates. By including technology as a learning support, the experience also aims at increasing the motivation of firstyear students, since they could see how innovative technology can be employed into real-life contexts. 241 students ranging in age from 18 to 25 years participated in the experience.

\subsection{The CSCBL scenario: Jigsaw CLFP applied to a blended learning scenario}

The Jigsaw CLFP organizes a complex learning flow for a context in which several small groups face the study of a lot of information for the resolution of the same problem (Hernández-Leo et al, 2009). The activity flow is structured into three phases: 1) an individual or initial group studies a particular sub-problem, 2) students involved in the same sub-problem are grouped in Expert groups in order to exchange ideas, and 3) students are grouped in Jigsaw groups, which are composed of one expert in each sub-problem, to solve the whole problem. This pattern provides students with three educational benefits: positive interdependence, discussion and individual accountability. Although there are studies that have applied this script in different contexts (Aronson et al, 2002; Hernández-Leo et al, 2007), none of them applied the pattern to a blended learning context. This section presents how we benefit from the Jigsaw CLFP structure, mobile technology and other computing tools to both capture the actions occurring in exploratory informal activities and use that information for designing the groups of people for next activities in the workflow.

The experience is divided into three phases (according to the Jigsaw CLFP):

1. "Discovering the Communication-Poblenou Campus" (adaptation of the individual phase): Students freely explore some selected areas of the campus in order to become familiar with the services provided. At the end of this phase, all the students are asked to fill in an online 
questionnaire about the different areas visited during the exploration, their preferred buildings and main services.

2. "Explaining the campus” (adaptation of the Expert groups' phase): Students are distributed by the teachers in groups of 5 or 4 people and assigned to one of the campus areas according to their expertise in the different buildings. Each group gives a presentation about the area assigned and uploads it into the Moodle platform. The teachers upload all the presentations into a public repository so that all the students can have access to them.

3. "Reflecting about the campus" (adaptation of the Jigsaw groups' phase): Due to the lack of hours for making oral presentations and the huge number of students registered to the subject, this activity is conducted individually. Each student reviews the presentations designed by their classmates and fills in a questionnaire of 20 questions about the campus.

\section{Implementation of the scenario}

One of the most relevant aspects for assuring a successful collaborative experience relies on the orchestration of the different phases (i.e. grouping students or distributing activities) (Dillenbourg, 2008; Dillenbourg \& Fischer, 2007). A step-by-step explanation of the workflow of actions conducted by both teachers and students, an overview of the technologies used and the results can contribute to gain a deep understanding of the CSCBL experience. A summary of the whole scenario detailing the data and outcome used for an integrated orchestration of the activity is presented in Table 1. At the end of this section, the technologies employed and developed for supporting and facilitating this orchestration are discussed. 
Table 1 Workflow and outcomes of the CSCBL scenario

\begin{tabular}{|c|c|c|c|c|}
\hline \multirow{3}{*}{$\begin{array}{l}\text { Learning } \\
\text { Flow } \\
\text { Phase }\end{array}$} & \multirow{3}{*}{ Teacher } & \multirow{3}{*}{ Student } & \multicolumn{2}{|c|}{ Data for the orchestration/Outcome } \\
\hline & & & & \\
\hline & & & Teacher & Students \\
\hline \multirow{2}{*}{ 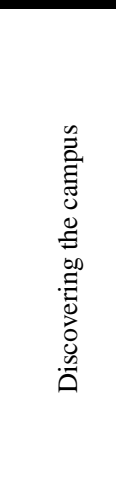 } & $\begin{array}{l}\text { Preparation of the activity } \\
\text { "Discovering the campus": } \\
\text { - Preparing the tags' content } \\
\text { - Recording the contents on the } \\
\text { tags } \\
\text { - Locating the tags on the } \\
\text { campus }\end{array}$ & $\begin{array}{l}\text { Choose the exploration activity: } \\
\text { - Activity "Discovering the } \\
\text { campus" with mobile devices } \\
\text { - Walk around the campus } \\
\text { - Visit the web page of the } \\
\text { campus }\end{array}$ & NFC tags & $\begin{array}{l}\text { Log files recording the } \\
\text { activity of the students' } \\
\text { actions during the } \\
\text { exploration with the mobile } \\
\text { devices ( } 73 \text { participants) }\end{array}$ \\
\hline & $\begin{array}{l}\text { Preparation of the test "Discover } \\
\text { the learning environment" }\end{array}$ & $\begin{array}{l}\text { Answering the individual } \\
\text { questionnaire "Discover the } \\
\text { learning environment" }\end{array}$ & $\begin{array}{l}\text { Individual } \\
\text { Mandatory } \\
\text { Questionnaire } \\
\text { "Discover the } \\
\text { learning } \\
\text { environment " in } \\
\text { Google Docs }\end{array}$ & $\begin{array}{l}\text { Answers "Discover the } \\
\text { learning environment" ( } 241 \\
\text { participants) }\end{array}$ \\
\hline 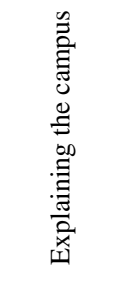 & $\begin{array}{l}\text { Preparation of the activity } \\
\text { "Explaining the campus": } \\
\text { - Experts definition depending } \\
\text { on students' activity and } \\
\text { preferences } \\
\text { - Form expert groups and assign } \\
\text { them an area of the campus } \\
\text { Prepare list of groups }\end{array}$ & $\begin{array}{l}\text { Preparing the presentation: } \\
\text { - Locate group members } \\
\text { - Prepare 6-slides' presentation } \\
\text { and upload to the Moodle } \\
\text { Course }\end{array}$ & $\begin{array}{l}\text { List of expert } \\
\text { groups assigned to } \\
\text { an area of the } \\
\text { campus }\end{array}$ & $\begin{array}{l}\text { Presentation of the area } \\
\text { assigned }\end{array}$ \\
\hline \multirow{2}{*}{ 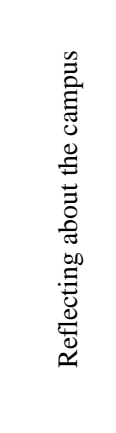 } & $\begin{array}{l}\text { Preparation of the activity } \\
\text { "Reflecting about the campus": } \\
\text { - Review and score presentations } \\
\text { - Prepare the mandatory } \\
\text { questionnaire in the Moodle } \\
\text { platform "Reflecting about the } \\
\text { campus" } \\
\text { - Final score: Average of } \\
\text { Questionnaire + Presentation }\end{array}$ & $\begin{array}{l}\text { Perform the activity "Reflecting } \\
\text { about the campus": } \\
\text { - Review other groups' } \\
\text { presentations } \\
\text { - Answer the mandatory } \\
\text { questionnaire }\end{array}$ & $\begin{array}{l}\text { Mandatory final } \\
\text { questionnaire. } \\
\text { Scores of the } \\
\text { presentations and } \\
\text { of the final } \\
\text { questionnaire }\end{array}$ & $\begin{array}{l}\text { Answers to the mandatory } \\
\text { questionnaire }\end{array}$ \\
\hline & $\begin{array}{l}\text { Prepare the voluntary test for } \\
\text { reflecting about the whole } \\
\text { experience }\end{array}$ & $\begin{array}{l}\text { Answer the voluntary } \\
\text { questionnaire giving the opinion } \\
\text { about the whole experience }\end{array}$ & $\begin{array}{l}\text { Voluntary } \\
\text { questionnaire } \\
\text { about the } \\
\text { experience }\end{array}$ & $\begin{array}{l}\text { Answers of the voluntary } \\
\text { questionnaire about the } \\
\text { experience }\end{array}$ \\
\hline
\end{tabular}

\subsection{Implementation of Phase 1: Discovering the Campus}

For the exploration, students had three different options: (1) to access the University Web Page

(UPF Webpage, 2010), (2) to walk around the campus, read the posters fixed on key areas of important buildings of the campus and ask other students more familiar with the campus, or (3) to participate in an exploratory activity using mobile phones. The students could choose one, two or the three options. 
The third choice was especially designed for the ICTI course. A set of 46 interactive tags containing information about the five main buildings of the campus were prepared and distributed along the different areas of the campus by two teachers. The teachers prepared and recorded the contents of the tags. The tags were recorded before the experience and not rewritten during the activity in order to facilitate the same information to all the students. The contents included audio files (mp3 format) explaining characteristics of the buildings and the services that they offered, image files (jpg format) and video files (3gp format) related to the area where the tags were located (contents produced can be accessed via the Web created for the experience (Meeting the Campus 2009 Website, 2010)). All the tags were fixed on a yellow card for facilitating their visibility and attached to the walls of the campus according to their content (see Figure 1). Students had 20-30 minutes to freely explore the different areas and to discover the information, which was hidden in the interactive tags, using a mobile phone. The stream of tags accessed by each student was stored in a log file in the mobile phones. Every student was provided with a mobile phone. Technical details about the tags and mobile phones employed the log files and the processes for writing and reading the tags are explained at the end of this section. After the exploratory activity, students had to fill in a web-based questionnaire in Google Docs (Google Docs, 2010). 241 students (74 chose the mobile experience and 167 other of the two options) answered this questionnaire. All the students were classified in different groups depending on the option selected for the exploration. Table 2 shows the final distribution of students. 


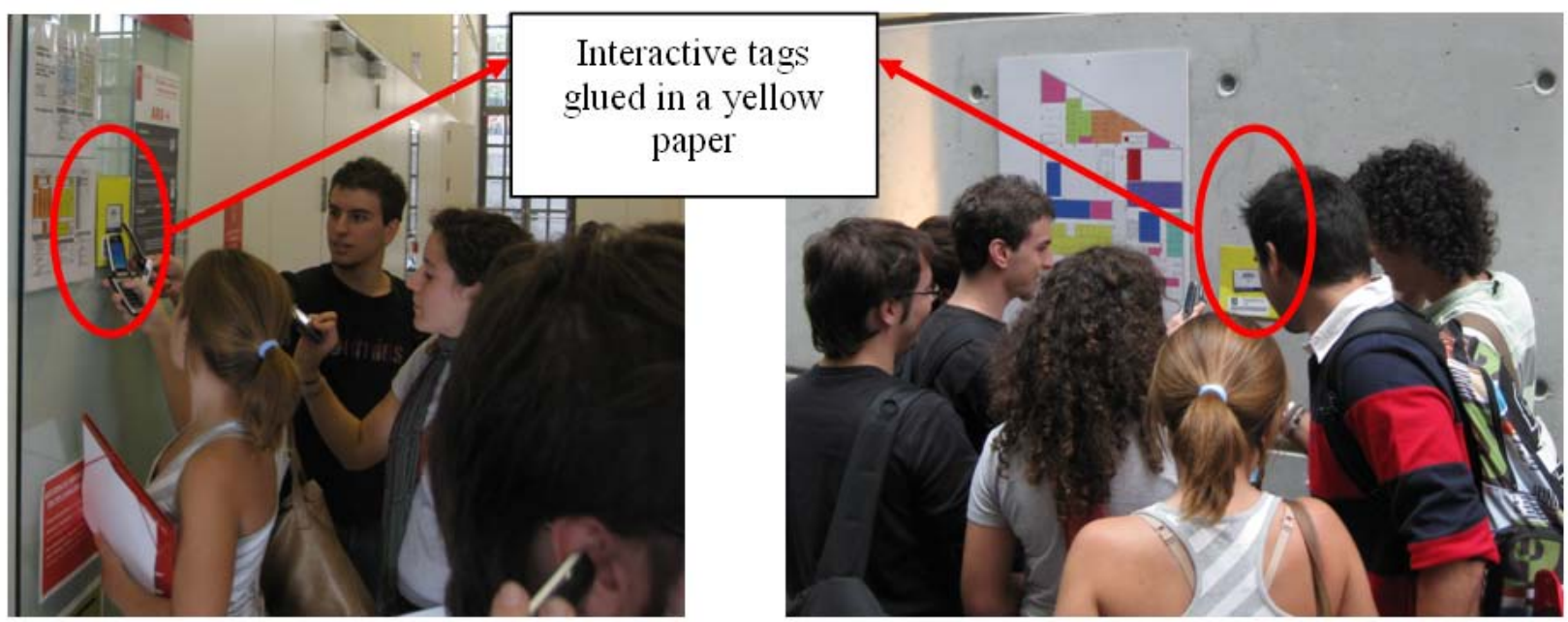

Figure 1 Students interacting with the 46 NFC Tags distributed around the campus. The tags are glued in a yellow card to make them more visible. Students access the information hidden in the tags with mobiles that integrate NFC reader and that were facilitated for the experience.

Table 2 Number of students that answered the questionnaires classified by the type of exploration performed

\begin{tabular}{ll}
\multicolumn{1}{c}{ Exploration type } & \multicolumn{1}{c}{ Answered the questionnaire } \\
\hline Expl. with mobile phones & 63 (in front of the 74 we have logs from) \\
Expl. by walking & 25 \\
Expl. by web & 108 \\
Expl. using three mediums & 8 \\
Expl. mobile \& web & 1 \\
Expl. mobile \& walk & 2 \\
Expl. web \& other (already visited, ...) & 9 \\
Already knew the campus & 2 \\
Total answering the questionnaire & 218 \\
Do not answer & 23 \\
Total & $\mathbf{2 4 1}$ \\
\hline
\end{tabular}

\subsection{Implementation of Phase 2: Explaining the campus}

The grouping and assignments in this phase required the adaptation of the concept of expert group of the Jigsaw CLFP, wherein expertise is defined by the topic or concept of study assigned to the student in the first phase. However, in the first phase of our experience, the students explored the campus on their own and no area was assigned to them. Thus, the expertise was defined by the particular actions conducted by each of the students in the first phase. The areas 
and buildings that each of the students visited (for those that performed the exploration with the mobile devices or the walk) or accessed (for those who preferred the web) determined the expertise that the student had in that area or building. Therefore, the personal experience of each student in an informal activity was a constraining factor that modified the activity.

The expertise of the students that conducted the activity with the mobile phones (experimental group or EG) was defined according to the number of tags of each area they visited during the exploration. Depending on the number of tags available in each building, the amount of tags accessed required for becoming an expert in that area was different (see Table 2 with the description of the constraints for each building). However, in order to have a more balanced number of people per building, some of the students were assigned to the second more visited building and not to the first one. For those students who carried out the exploration following any other methods from Table 3 (control group or CG), their expertise was defined according to the results of the questionnaires. We analyzed the question asking the students to list the buildings visited/accessed and that about recommending one building to their colleagues in order to define their expertise.

Table 3 Number of tags available per building and minimum number of tags required for becoming an expert in each of the buildings

\begin{tabular}{|c|c|c|}
\hline Building & $\begin{array}{l}\text { Number of } \\
\text { tags available }\end{array}$ & Number of tags required for becoming an expert in the building \\
\hline $\begin{array}{l}\text { Roc Boronat (52 } \\
\text { and 53) }\end{array}$ & 13 & $\begin{array}{l}\text { More or equal to } 4 \text { (Most of the students only accessed to the tags located in the first floor of the } \\
\text { buildings) }\end{array}$ \\
\hline La Nau & 8 & More or equal to 5 \\
\hline Tanger & 11 & More or equal to 4 \\
\hline Tallers & 4 & More or equal to 2 \\
\hline La Fàbrica & 10 & More or equal to 4 \\
\hline
\end{tabular}

Once the buildings were assigned, the students were distributed randomly in groups of 4 people with the same expertise and classified depending on the medium used for the exploration in: MOBILE (conducted the exploration with mobiles), OTHER (conducted the exploration via web or walking) and MIX (two from MOBILE and two from OTHER). The list of group assignments 
was delivered to the students via the Moodle learning management system. Students contacted their groups' members mainly using e-mail. Students uploaded their final presentations one week later via Moodle. Table 4 shows the actual distribution of students in groups including only those students that finally delivered the presentation (only 9 students from the 241 listed from the beginning did not deliver the presentation).

Table 4 Number of students for each of the group types defined (including only those students that finally delivered the final presentation)

\begin{tabular}{lcccc}
\hline \multirow{2}{*}{ Type of group } & Number of groups & Experimental students & Control students & Total of students \\
\hline Only Mobile & 11 & 43 & 2 & 45 \\
Other mediums & 37 & 6 & 136 & 140 \\
Mixed & 14 & 27 & 29 & 56 \\
Total & $\mathbf{6 2}$ & $\mathbf{7 4}$ & $\mathbf{1 6 7}$ & $\mathbf{2 4 1}$ \\
\hline
\end{tabular}

\subsection{Implementation of Phase 3: Reflect about the campus}

The presentations were uploaded by the teachers to the Moodle course platform. Students from the different groups had 5 days to access and review the presentations from their classmates. The individual final questionnaire was filled in a 25-minute practical session in the subject. The questionnaire had 25 questions, all of which related to common aspects described by the students in their final works.

\subsection{Technical details of the technological environment}

Figure 2 shows a general schema of the technological environment supporting the experience as a unique integrated learning setting. The schema is organized according to the phases of the experience. NFC Mobile phones and NFC tags were the support for the campus exploration. Software tools were developed for writing and reading the tags. Bluetooth technologies were used to collect the log files resulting from the exploratory activity. Finally, Moodle and Google Docs were the web-based software tools employed for editing and answering the questionnaires 
and for uploading and sharing the final works. In the following subsections we describe the details of all these technologies and software tools adopted and developed for the experience.
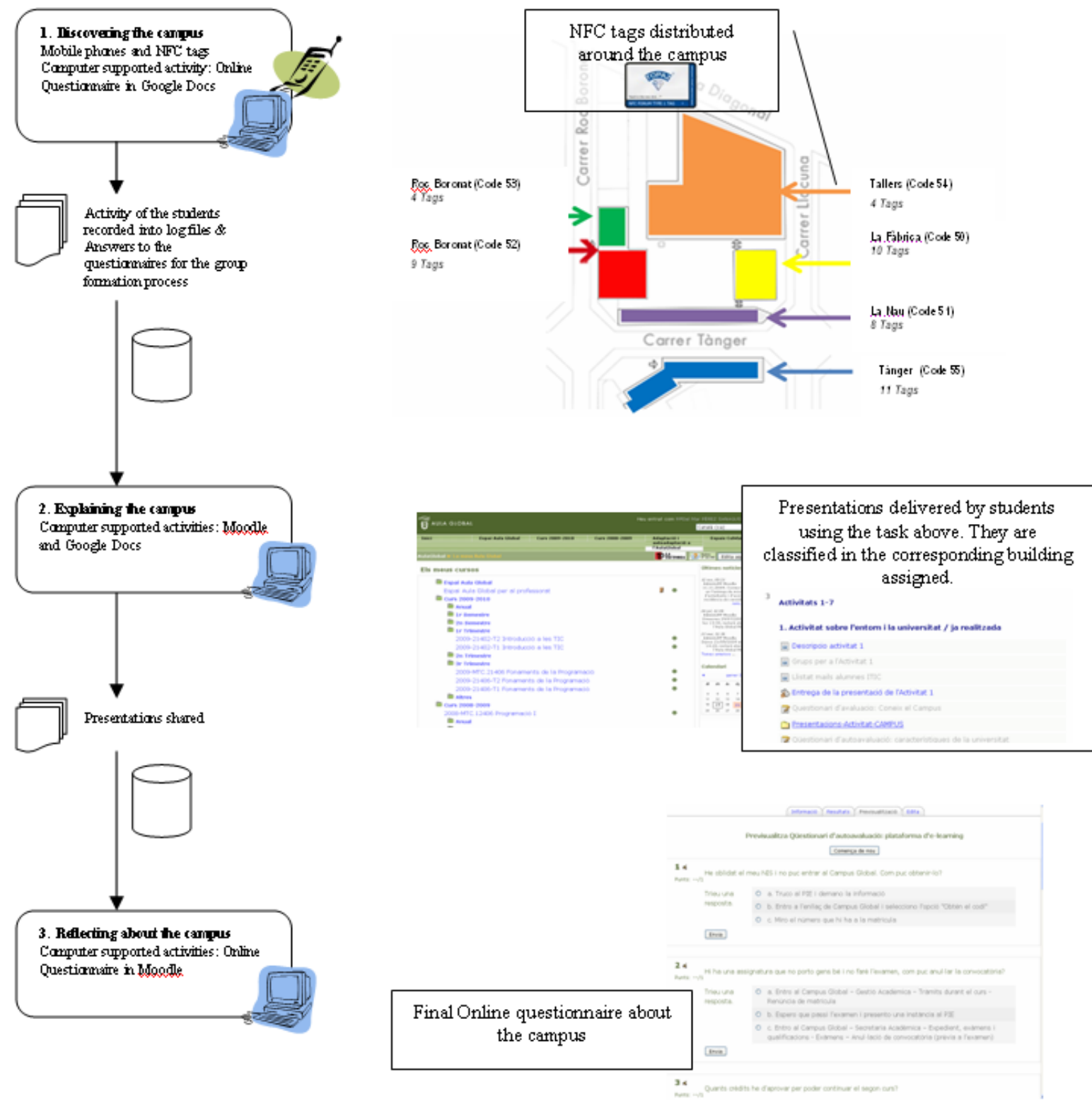

Figure 2 Technological environment: A combination of mobile devices with an integrated NFC reader, NFC tags, a Moodle Platform and Google docs allows an integration of the different activities of the learning flow into a unique learning setting. 


\subsubsection{Architecture of the NFC Mobile phones}

The mobile phones employed for the experience are NOKIA (N6131, N6212), which include an embedded RFID/NFC reader (Manish \& Shahram, 2005; Sweeney, 2005). These mobile phones offer a J2ME API with NFC functionalities. Figure 3 shows the NFC Mobile phones architecture.

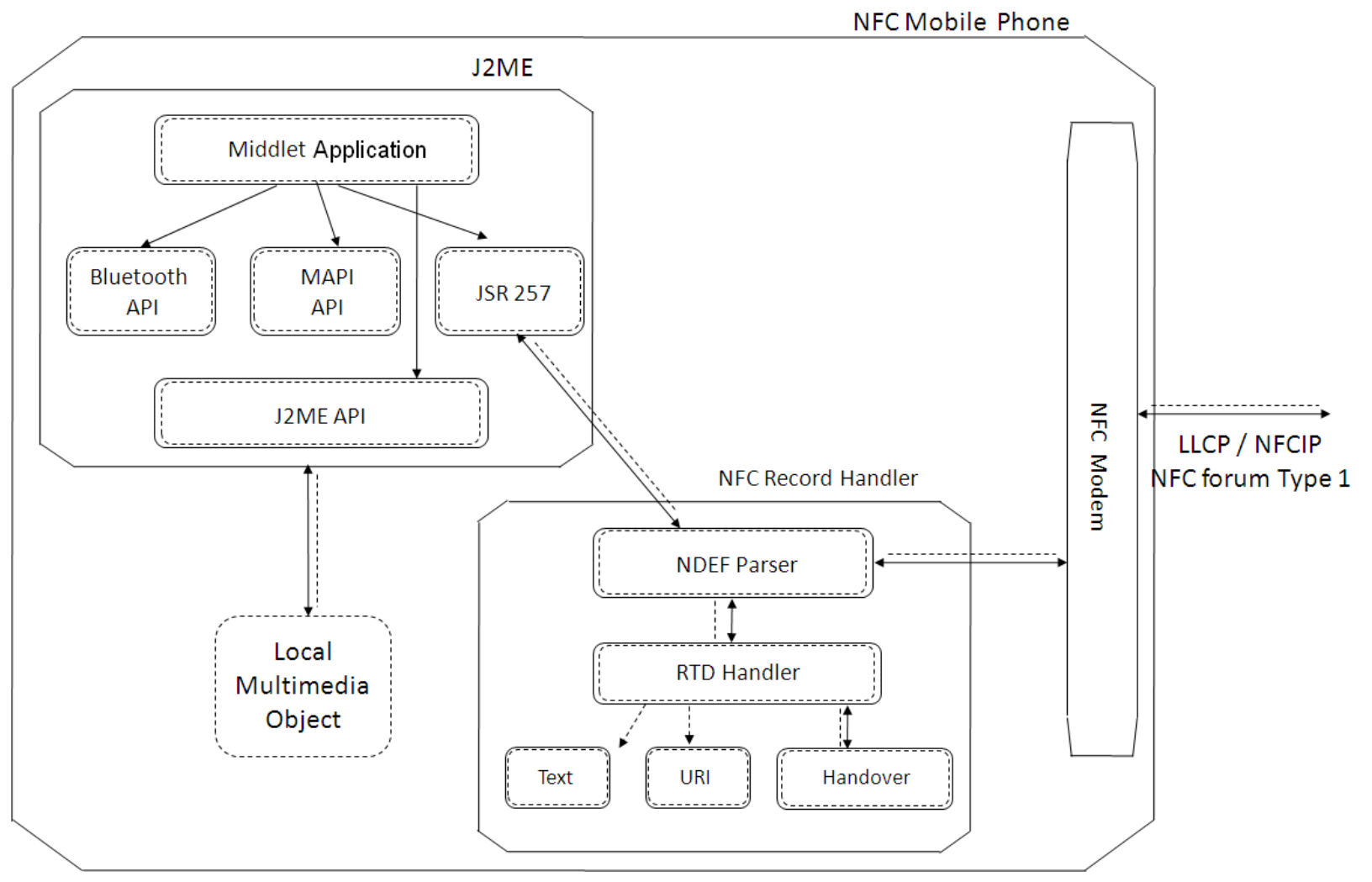

Figure 3 Detailed architecture of the NFC mobile phones employed for the experience

These mobile phones encapsulate the data following a NDEF (NFC Data Exchange Format) format, which follows the specification NFC Record Type Definition (RTD) (N. Forum, 2007). The information exchanged can be a text or a URI (Uniform Resource Identifier), according with the NFC Text RTD (N. Forum, 2006) and the NFC URI RTD (N. Forum, 2006) specification, respectively. The information exchanged with the tags is determined by the NFC Forum Type 1 Tag (N. Forum, 2010) specification which, at the same time, is based on the ISO/IEC 14443A specification. The basic communication with the tag follows the NFC Logical Link (LLCP and 
IS/IEC 18092:2004 protocol (N. Forum, 2009), which implements the NFCIP-1 for the point-topoint communication. The handover implements the structure and sequence of interactions that enables two NFC-enabled devices to establish a connection using other wireless communication technologies, such as WiFi or Bluetooth.

The more important API used is the JSR 257. This API manages the data flow from the modem NFC for communicating with the NFC Record Handler. The rest of the APIs (Bluetooth and MAPI) are employed for connecting with the computer and multimedia management.

\subsubsection{NFC tags and software developed}

The contents were recorded by the teachers in the NFC tags and stored in the mobile phones. Each tag operates on the Near Field Communication (NFC Forum, 2007) standard, the tags used are TOPAZ tags provided by Innovision (Innovision Research \& Technology, 2010). For writing, storing, reading and communicating with the NFC tags, a suit of J2ME application as well as a Java PC server were especially developed for the experience (download these applications at Meeting the Campus 2009 Website (2010)). We describe below these applications.

- NFC Player is used by the students for reading the content of a tag (Figure 4). When the application is executed shows the message "Touch the Object". If the user touches a NFC tag, the path where the content is stored into the Mobile phone appears on the screen. When pressing select, the corresponding audio, video or image file is reproduced. When a tag is touched, the register of the activity is always updated with the information of the tag and the time in which it was accessed. 

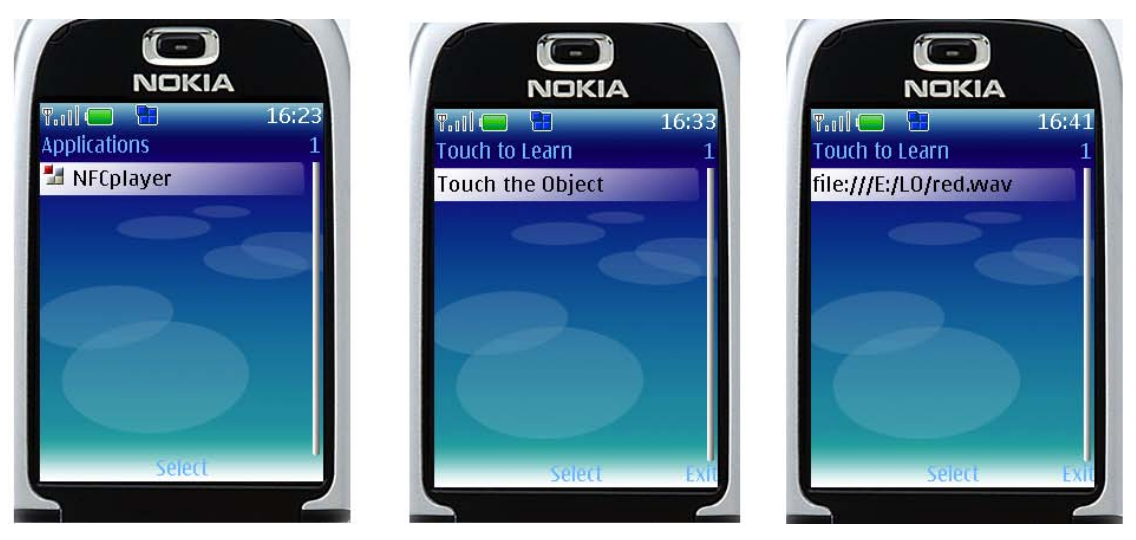

Figure 4 NFC Player application usage.

- ReadOnlyBD shows the activity register of each mobile (which was related to one student in this case). When executed, the application shows on the screen the list of objects that have been accessed (visualized by the students) with the date and the time of access (Figure 5). During the experience, teachers used this application to test whether the information about the route of each student was correctly recorded.
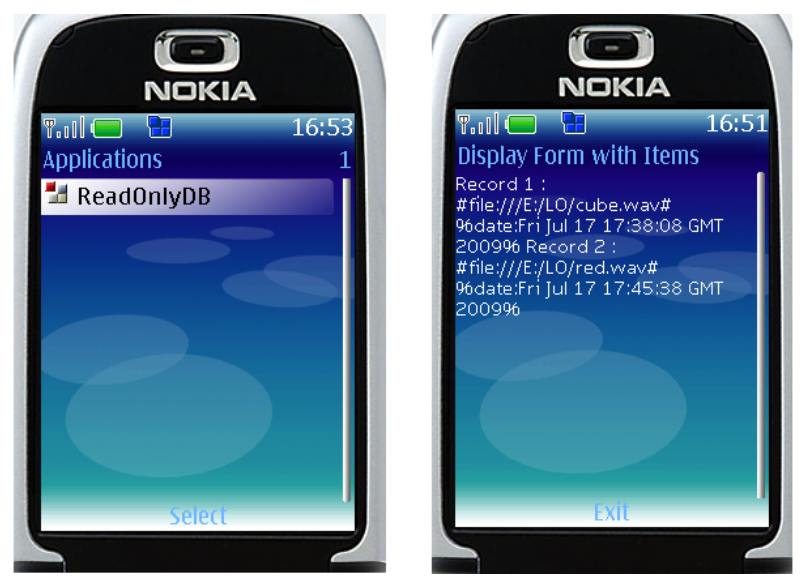

Figure 5 ReadOnlyBD application usage.

- ReadWriteTags was employed by the teachers to record all the information about the campus in the tags. To write the information on a tag, the user has to select "Write" and inserts manually the path corresponding to the content location in the mobile phone. For the experience, all the contents were stored in the same path of the mobile phones. Once the 
information is written, the user has to touch the tag and wait until the application indicates that the information has been successfully recorded. If the tag has been correctly updated, the word END will be shown (Figure 6). The user can test whether the path is stored in the tag selecting "Read" and touching the tag. Tags can be rewritten as many times as the user wishes. However, as we have already mentioned in section 3.1, for this experience, the tags were recorded once before the experience and not rewritten during the activity.
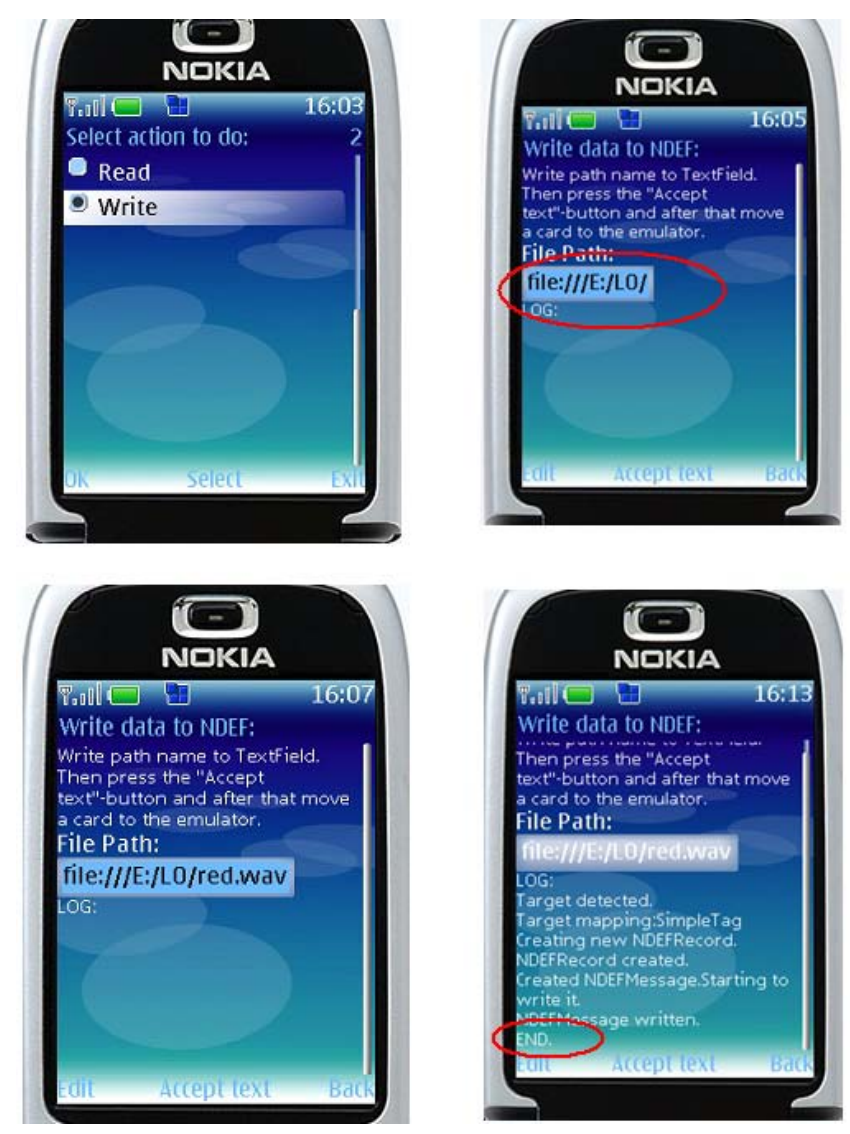

Figure 6 ReadWriteTags application usage - “Write” functionality.

- send2server was used by the teachers to send the registration of the students' activity stored in the mobile (the log files). This was done when they finished the exploratory activity. When the application is executed, the mobile phone connects and sends the log 
files automatically to the computer. This application works together with the application BT Bridge.

The application BT Bridge, based on Bluecove Project (Bluecove, 2010), was developed to connect the mobile phones with the teachers' computer and extract the information of the log files. This application works under Windows operating system (XP and Vista) with Bluetooth enabled. When BT Bridge is executed, a pop up window indicating that the connection is being processed is displayed.

Once the connection is successfully established, the activity stored in the mobile phone is automatically downloaded to the computer into the path previously indicated by the user. The information about the activity is a log file with the name of the tag that was used to identify the student. Figure 7 shows an example of these log files. Each log file is then analyzed by the teachers so as to classify the students in expert groups as explained in the previous section.

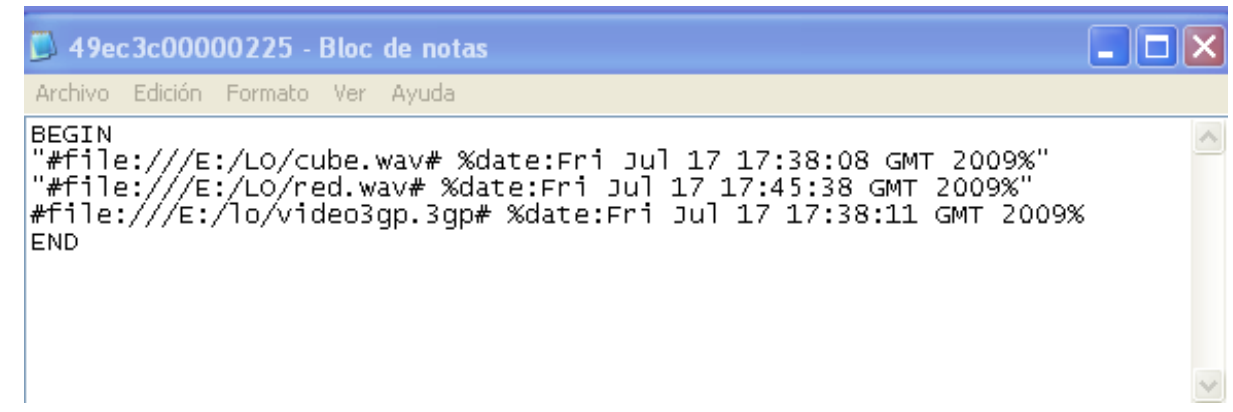

Figure 7 BT Bridge application usage - Log file generated and stored in the computer after the exploratory activity. There is one log file associated to each of the students participating in the activity.

\subsubsection{Web based tools}

Moodle is a Learning Management System for producing Internet-based courses and web sites. Moodle can be installed in any system with PHP and a SQL type database and runs under any operating system (Moodle, 2010). UPF provides students and teachers with Moodle, the 
institutional learning management system. In this case study, teachers created (according to the terminology used in Moodle) an 'activity project' so that the students could upload their final presentations and share them with their classmates. The questionnaire filled in during the final phase (reflecting about the campus) and the final marks were delivered through this platform as well.

Google Docs is a web-based application by Google for creating, sharing and collaboratively editing word files, presentations, spreadsheets and forms (Google Docs, 2010). The service is supported on Firefox, Internet Explorer, Safari and Chrome browsers running in any type of operating system. Google Docs supports the ISO standard OpenDocument format and other proprietary formats (.doc, .xsl...). For the experience, Google Docs was employed by the teachers for preparing the post-exploratory questionnaire. The spreadsheet with the responses generated was used for recovering all the information about the knowledge of the students about the campus after the exploration.

Both Moodle and Google Docs are cloud computing software applications, which facilitates a ubiquitous access by the students avoiding problems such as software incompatibility issues.

\section{Evaluation of the Case Study}

The main goal of the case study is to evaluate the effectiveness of adopting a CLFP through the use of mobile and other technologies, in order to create an effective CSCBL experience which aids students in their transition to university. The evaluation focuses on whether the application of a CLFP for orchestrating both informal and formal activities facilitates the students in their first experience with the campus services and the university community members, methodologies and activities. The evaluation also aims to assess the motivational benefits of the activity proposed and its educational innovation with respect to more classical introductory experiences. Finally, the evaluation of this case study intends to identify the main successful aspects and 
limitations experimented by both teachers and students during the orchestration of the CSCBL experience. This issue may aid in highlighting the strengths and weaknesses of the whole scenario, and the technical environment, for further improvements.

\subsection{Evaluation Methodology}

Rather than proofing or rejecting a research hypothesis, the aim of the evaluation methodology of for this exploratory case study is to identify tendencies in the aforementioned issues in this particular learning context. To this end, all the data gathered through several methods is aggregated and analytically compared using a mixed evaluation method (Martínez-Monés, 2002; Frechtling \& Sharp, 1997). This method combines quantitative techniques and sources, such as closed questions or event log files generated automatically by the mobile phones, with qualitative techniques, such as open-ended questions and first-hand observations. All this information is analyzed and triangulated by using the triangulation method (Gahan \& Hannibal, 1998; Guba, 1981). The triangulation consists in analyzing each conclusion from a different perspective in order to have several confirmations supported by both qualitative and quantitative data.

Table 5 shows all the data sources that were used to evaluate the case study according to the mixed method. Students' perceptions about the exploratory experience with the mobile devices were collected in a paper-based questionnaire delivered immediately after the exploration. This data was also combined with first-and observations gathered by four different observers that followed the students during the visit (time) through the campus and with the data extracted from the exploration video recordings. The observers write down their comments on a template facilitated by the authors in which they have to indicate the time of the observation. Quantitative ratings, qualitative comments and opinions about the visit around the campus (physically or virtually) were collected in an online questionnaire, which was filled in by students after the 
exploration. Quantitative and qualitative results about the knowledge gained were obtained from two sources: (1) the score average of the presentations (two different teachers evaluated each presentation), (2) the automatic scoring of the mandatory individual Moodle web-questionnaire about the campus and (3) comments gathered from teachers' and students' questionnaires and observations. Finally, data regarding the orchestration of the activity was obtained from quantitative ratings and open explanations provided by the two teachers of the course in a webbased questionnaire.

Table 5 Data sources for the evaluation of the case study and labels used in the text to quote them

\begin{tabular}{|c|c|c|}
\hline Data source & Type of data & Labels \\
\hline $\begin{array}{l}\text { Questionnaires about the exploratory experience } \\
\text { of the campus with mobile phones (only } \\
\text { performed by those students who made the } \\
\text { experience with mobile devices) }\end{array}$ & $\begin{array}{l}\text { Qualitative numeric data, comments and } \\
\text { opinions }\end{array}$ & [Quest-Experience-eg] \\
\hline $\begin{array}{l}\text { Mandatory Questionnaire about the "campus } \\
\text { exploration" }\end{array}$ & $\begin{array}{l}\text { Quantitative data about the places visited } \\
\text { Qualitative data, comments and opinions of } \\
\text { the different areas }\end{array}$ & [Quest-Campus-Phase1] \\
\hline $\begin{array}{l}\text { Grades of the presentations resulting from the } \\
\text { Phase of Experts }\end{array}$ & $\begin{array}{l}\text { Quantitative results obtained from the } \\
\text { average of the final score given to each } \\
\text { presentation by two different teachers }\end{array}$ & [Presentations-Score-Phase2] \\
\hline $\begin{array}{l}\text { Questionnaire about the "campus knowledge } \\
\text { acquired" }\end{array}$ & $\begin{array}{l}\text { Quantitative results from an automatically } \\
\text { evaluated questionnaire performed in } \\
\text { Moodle }\end{array}$ & [Quest-Score-Phase3] \\
\hline $\begin{array}{l}\text { Optional final questionnaire about the grouping } \\
\text { policies carried out in the experience }\end{array}$ & $\begin{array}{l}\text { Quantitative ratings and qualitative opinions } \\
\text { about the whole activity process focusing on } \\
\text { the policies used for the group assignments }\end{array}$ & [Quest-Reflection-Phase3] \\
\hline $\begin{array}{l}\text { Observations from four researchers external to } \\
\text { the case study }\end{array}$ & $\begin{array}{l}\text { Record of direct observations during the } \\
\text { experience by } 4 \text { different researchers }\end{array}$ & $\begin{array}{l}\text { [observer1, observer2, } \\
\text { observer3, observer4] }\end{array}$ \\
\hline $\begin{array}{l}\text { Videos of the students performing the } \\
\text { experience with mobile phones }\end{array}$ & Qualitative data & $\begin{array}{l}\text { [video-Learn3- } \\
\text { Transcriptions] }\end{array}$ \\
\hline $\begin{array}{l}\text { Questionnaire about the orchestration process for } \\
\text { the teachers }\end{array}$ & Qualitative data & [Quest-teachers] \\
\hline
\end{tabular}




\section{Results and Discussion}

Table 6 shows an overview of the main findings of the research. Experimental Groups (EG) refers to those students that performed the activity with mobile phones. Control Group (CG) refers to those student that did not conduct the activity with mobile phones. 
Focus 1. Meaningfulness of the CSCBL activity generated.

Applying a CLFP to a blended learning - The students that were physically in contact with the campus show more precise scenario using mobile technologies is a good approach for supporting the integration of formal with informal exploratory activities. via the web. better results in average and have developed more original contents in their descriptions of the university service's locations that those who only did the exploration

- The scores of the whole activity show that students in the experimental group show presentations.

- Groups formed by students from MOBILE and MIX groups have better scores that those from the WEB group.

- The students from WEB group did more errors in the individual questionnaire when they were asked to locate some of the services of the University.

- Students contact with the different services of the university and activities of the department.

The CSCBL experience, which

- The combination of informal and formal activities is a good support for learning non typical contents about the campus and services.

and individual with group ones, facilitates the students to have a first contact with the academic methods and useful services that will help during their engineering studies in the future. Moreover, working in groups formed based on the students' personal experience is shown to be a successful mechanism for promoting collaboration.

- The variety of activities makes it easier to make students comfortable with the activity as a whole.

- The combination explorative activities in combination with reflective tasks such as the individual questionnaires reinforce learning.

- Combining types of individual activities with work in groups is a good mechanism for learning about the different studies' methodologies.

- Students have adapted to work with the group imposed by the teacher and collaborated successfully.

- The grouping policies based on log files are a good method to facilitate the students to meet meet each other.

- The experience is successful in promoting collaboration.

Focus 2. Motivational benefits of the activity proposed and its educational innovation with respect to more classical introductory experiences.

Students highly appreciate the CSCBL - The exploration using mobile technology is a good support for learning and discovering scenario compared with their previous more about the campus structure and services in comparison with other activities.

experiences in terms of innovation, use - Students value experiences that combine technologies such as mobile devices as very of supporting technology and discovery. fun, innovative, interesting and useful.

- Students recommend the activity because of the innovative use and manipulation of technology.

The inclusion of free exploratory experiences technologically supported in a formal sequence of activities fosters the students' motivation on the studies, the University services and their interest on technology.

- The use of mobile technologies for the exploration-type of activities supports the discovery of different places and enacts the motivation of students with regards the university activities (including research).

- Students value the CSCBL experience as very good for discovering departments and services of the university that will be useful for them in the future.

- The majority of the students will repeat the explorative experience of the campus and recommend others to perform it because of its utility to learn about it.

Focus 3. Successful aspects and the limitations experimented by teachers and students during the orchestration of CSCBL experience.

The network and computer technology used in the CSCBL experience (mobile phones, NFC/RFID, Moodle platform and Google Docs) has been easily adopted by the students and the teacher during the whole activity. However, some usability and integration aspects should be improved.

The CSCBL scenario and technological environment developed is shown as a good solution for integrating informal exploratory activities with formal activities, for fostering collaboration and supporting its orchestration. However, an integrated system for blended activities flow would facilitate the data acquisition from the exploratory activity and help in the group formation processes for a better adoption of the CLFP.
- Students suggest other technologies such as PDAs for facilitating the access to content such as video or images.

- The use of mobile devices enables the generation of informal activities that balance flexibility and guidance.

- Students have easily managed the University’s Moodle platform.

- The audio-contents should be improved by turning up the sound of the registrations.

- The mobile device application could be improved by including the possibility of accessing the same tag with two different mobiles at the same time and making it more robust for reading the tags.

- Log files for storing the actions of the students during the exploratory experience are a good support for the integration of formal and informal activities occurring in different spaces.

- Log files capturing the actions of the students in combination of online questionnaires is a good technological support for defining expert groups by fostering collaboration.

- Students highly appreciate the experience with the mobile devices and suggest increasing the time of the exploratory experience.

- Results show that the best policy for acquiring good learning outcomes is to group people with the same interests (in this case interested in doing the exploration with the mobile phones) or mix them in equilibrated groups (two from each type). These types of grouping policies are possible thanks to the NFC technology or other tracking tooling.
[Quest-Campus-

Phase1]

[Quest-Reflection-

Phase3]

[Presentations-Score-

Phase2]

[Quest-Score-Phase3]

[Quest-Score-Phase3]

[Quest-Reflection-

Phase3]

[Quest-Experience-eg]

[Quest-Reflection-

Phase3]

[video-Learn3-

Transcriptions]

[observer1, observer2, observer3, observer4] [Quest-Reflection-

Phase3]

[observer1, observer2, observer3, observer4]

[video-Learn3-

Transcriptions]

[Quest-teachers]

[Quest-Reflection-

Phase3]

[Quest-Experience-eg]

[Quest-Campus-

Phase1]

[Quest-Experience-eg]

[Quest-teachers]

[Quest-Reflection-

Phase3] 
The first focus of the analysis should indicate whether the resulting CSCBL scenario is effective for the students to meet the campus, its services and other their course mates. The first finding in Table 6 shows that using mobile technologies in a CLFP-based blended learning scenario is a good approach for supporting the integration of formal and informal exploratory activities into a unique learning setting that facilitates the students discovering the campus.

Students in EG obtained better presentations score than those grouping CG (upper image in Figure 8). The Kruskal-Wallis Test (taking as independent variables the type of exploration conducted) applied to the samples of exploration with mobile phones, walking and via web shows that the means sample differs significantly between groups ( $\mathrm{p}<0.001)$. Moreover, the final score in average (presentation plus final test scores) of the students that partook in the experience with mobile phones is 7.85 (SD deviation of 0.66 with $\mathrm{N}=59$ ) over the 7.50 (ST deviation of 0.64 with $\mathrm{N}=84$ ) that did the experience with the web (lower image in Figure 8) [Quest-Score-Phase3, Presentations-Score-Phase2]. Although the differences in scoring between the EG and the rest were not very high, open-end questions in mandatory questionnaires show that these students made more precise descriptions of the University service's locations and included more original contents in their presentations than those who only did the exploration via web [Presentations-Score-Phase2, QuestReflection-Phase3]. For example, one of the students explained “...on the walls of the bar you can find advertisements offering or asking for rooms to rent or notes demanding lost objects. There you also find a microwave for heating up the food you bring from home... [Quest-Campus-Phase1]" and other mentioned one of the most famous musical instruments created in the department "On the third floor there is the MTG (Music Technology Group) which created the Reactable [Quest-CampusPhase1]”. Most of the comments made by students in EG are related to information included in the 
tags or about the university building. This information is not easy to find through the web of the university. Furthermore, students that worked only with the web made more errors in their descriptions than those who did the exploration with mobile phones and tended to copy directly the content from the web when describing the services [Quest-Campus-Phase1].

The second finding shows that the CSCBL helps first-year students to have a first contact with the University methodologies and services which might be useful for them during the rest of their studies. When students reflected about their preferred experience, 14 (out of 175) preferred the activity of studying the presentations of their colleagues, 33 preferred working in groups, 20 preferred the individual questionnaires, 91 preferred the campus exploratory experience and 17 answered that they do not know [Quest-Reflection-Phase3]. This data shows that including different types of activities in the same experience increases the possibilities of satisfaction of a higher spectrum of students, which augments their possibilities of success in an introductory type of activity. Students also rated very positively the possibility of combining individual and group-based activities and of mixing exploratory with more reflective activities. 61 over 174 students marked in the final questionnaire that the group activity "helped them very much" to reflect about the exploratory experience and 54 said that the activity "helped them" [Quest-Reflection-Phase3]. Working in groups wherein students share very similar personal experiences turned out to be a successful mechanism for promoting collaboration. Most of the students adapted successfully to the work in groups defined by the teacher. Students were also aware of the benefits of this activity as a mechanism to experiment new work methodologies and to acquire new competences: “Working in groups has helped me a lot because I've exchanged information and I've learnt new methods for searching for information [Quest-Reflection-Phase3]” or “...Working in groups allows each of the members to contribute in the task and meet up new people [Quest-Reflection-Phase3]”. Students considered that mixing learning activities about services was very useful for their future studies. 
"[...] this activity has shown me how to do essential resources such as the copy machine or the book search of the library website [Quest-Reflection-Phase3]"; "this activity has allowed me to know about the library services [Quest-Reflection-Phase3]”. All students succeeded in using the online platform based on Moodle for submitting their assignments and filling in the questionnaires [Quest-ScorePhase3]. 

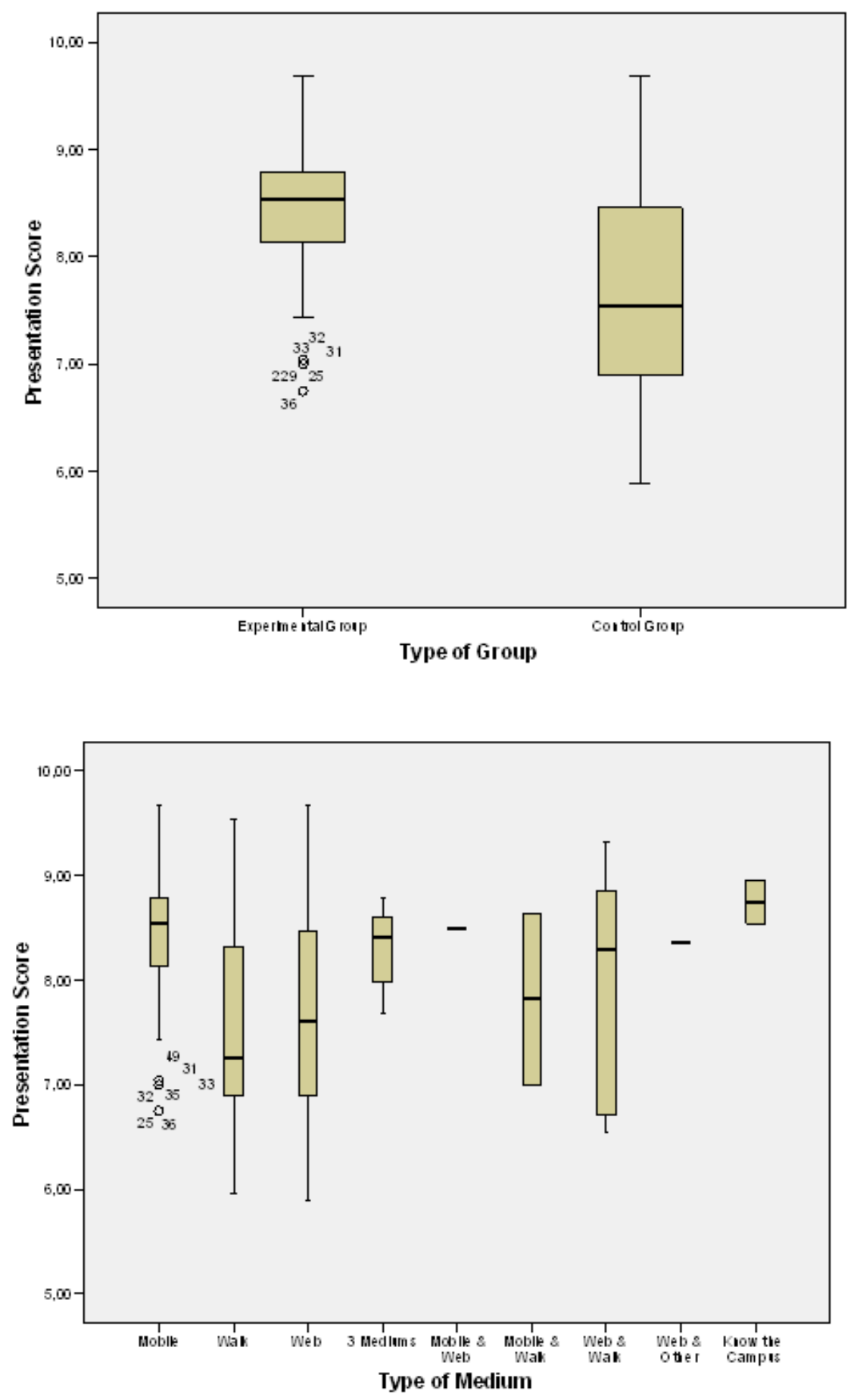

Figure 8 Presentations score separated by type of groups (upper figure) and mediums used for the exploratory activity (bottom figure). 
The second focus (2) of the research was to identify the motivational benefits of the CSCBL experience, and to understand its innovative educational aspects. We compared the observations and comments of the experimental (EG) with the control group (CG). This was done because we consider that the innovative aspect of the CSCBL scenario is the integration of an exploratory activity with mobile phones for influencing next activities in the workflow. 74 of 241 potential students participated voluntary in the activity [Quest-Experience-eg]. 46.25\% of the participants carried out the activity because they regarded it as innovative and $47.50 \%$ because they were curious about it [Quest-Experience-eg]. Students used adjectives such as "fun”, “different” and "useful” for describing the experience and recommended it to others due of its innovation and usefulness for learning [Quest-Experience-eg]. One participant reported "I would recommend the experience with the mobiles because it's an innovative activity (from my point of view) that helps you discover lots of hidden corners of the campus through an innovative and curious mechanism [Quest-Reflection-Phase3]”. Students preferred these activities instead of formal academic tests. For instance, "the activity is interactive while the questionnaires can be answered only with the web site of the University. In this last case you loose the information of the physical situation of the buildings [Quest-ReflectionPhase3]". Moreover, students who did not perform the mobile activity reported that they would participate in it provided that they were given a chance [Quest-Reflection-Phase3]. Students also regarded learning in situ as very a valuable activity for having a more detailed perspective of the campus: "the exploratory experience has been the funniest activity and helped me know the campus and discover research works carried out here [Quest-Reflection-Phase3]”. 113 (of 176 students) who conducted the last voluntary questionnaire for reflecting about the experience answered that they would repeat the activity [Quest-Reflection-Phase3]. Therefore, there is room for claiming that students 
appreciated the CSCBL activity highly. This was because of the innovative use of technologies and their usefulness for learning about the campus.

The second finding shows that the type of exploratory experience proposed enhances students' interest in technology and fosters their motivation with regard to their studies, engineering research and teaching activities. The in-situ observations confirm the positive attitudes that the experience enacted from the students while discovering research activities conducted at UPF. Two observers wrote "students enter any opened room and get surprised when they find a playstation [observer2]" and "when students see (in a video content) a robot from the SPECS research group they ask whether it has been done here [observer3]". Other observed wrote down "I have learnt how to manipulate technology such as mobiles and tags [Quest-ReflectionPhase3]”. Other comments reveal that the integration of this type of activities enhance the interest in the studies “(...) and the service that I liked to discover the most were the technological installations for image and audio because this type of technology is the reason that made me choose these studies [Quest-Reflection-Phase3]". It is worth mentioning that since the students using the mobiles phones decided themselves to carry out such activity, they might already be more motivated that the other group of students. However, it is also true that the activity with mobile phones was performed in the afternoon, while the in-class activities were always conducted in the morning, and a significant number of students worked or had another activity in the afternoon that may had hindered their participation in the mobile experience. Finally, students considered the activity helpful for knowing better the campus, and suggested increasing the length of the exploratory activity: "The exploratory experience with the mobiles is a very good activity because it allows you to become familiar with the campus. Nevertheless, I suggest extending the time for the exploration because, in half an hour, you haven't enough time to visit all the buildings [QuestReflection-Phase3]”. 
The final focus (3) of the analysis is related to the orchestration aspects of the CSCBL experience and the technological environment developed for its support. The first finding shows that the actual technology used during the activity was easily adopted and highly accepted by students and teachers. Regarding the mobile technology, $81.40 \%$ of 73 students participating in the exploration with mobile devices rated the use of NFC technology as useful or very useful [Quest-Reflection-Phase3]. Teachers succeeded in implementing part of the activities with the mobile phones with the support of an expert at NFC and managing the Moodle platform. Their comments are more related to the preparation of the material for the activity than with the technology in itself: "With some help from experts on NFC we were able to implement the part of the activity with the mobile phones. Creating the content was time consuming but not difficult [Quest-teachers]”. Teachers showed a big interest in the technological environment, in that it allowed (i) the possibility of saving the actions conducted by the students in their mobile phones, (ii) them to have an overall picture of what happened during the experience and organize the groups according to the students' actual experiences. Nevertheless, observations from the researchers and suggestions made by the students point out that some technological problems emerged during the activity. One of the major concerns was the volume of some of the audio-contents. Students had problems listening to the explanations from the mobile devices in open spaces, because the sound was very low [Quest-Experience-eg, observer3]. The video images also show how the students used their hands as amplifiers for hearing better the audio [video-Learn3-Transcriptions]. Suggestions were made to use headphones or improve the quality of the audio. Finally, the results show that the adoption of the Jigsaw CLFP and the technological environment developed can generate and orchestrate rich collaborative blended learning flows with potentially effective educational benefits. For the first exploratory phase, when students who participated in the mobile experience were asked whether the activity was useful for learning, 71 (of 74) answered 'yes' and 
appreciated the balance between the guidance supported by the mobile devices and the freedom enabled by the informal activity [Quest-Campus-Phase1]. Comments from the students corroborate this statement: "with the mobiles you can obtain a better guided visit of the campus [Quest-Experience-eg]", “... it's a good way of discovering the campus because, when you're a new student, you're lost [Quest-Experience-eg]”. For the preparations of the second phase, results show that mobile technology with the NFC tags and log files can keep a record of the actions conducted by students in different areas and suggest group distributions which foster collaboration. It is also evident that these actions, together with online questionnaires, are an effective solution for supporting the formation of expert groups. Most of the comments were related to the learning benefits of working in groups and one of the students commented on their relationships with the members of his / her group: "My group helped me because all the members were interested in the same area of the campus and, when there are common interests your motivation is increased and you do things better [Quest-Reflection-Phase3]”. Teachers rated the activity and the technological environment as very helpful for supporting learning. They argued for organising this experience in future courses: "1. The activities are more significant to them (they experience the services of the University vs. they just hear about the services). 2. Students are active in the whole activity. Also, thanks to working physically with what they are learning, they have the opportunity to discuss with other students the buildings/services of their interest, to discover other buildings/services by explanations of their own classmates, etc. 3. Students make use of ICT technologies that they will be learning in their studies they are just starting (again enhances the significance of the activity) [Quest-teachers]". Teachers also regarded a number of logistic aspects as demanding and time consuming. The coordinator of the activity reported: “Once the whole activity was set-up, I think it was more a matter of complexity than of difficulty. Again, the logistic was the more demanding issue: managing groups (creating groups, informing students about the groups, orchestrating 
their tasks depending on the groups, managing and analyzing their outcome in order to propose them the following tasks, managing their outcomes in order to facilitate the assessment of their learning, etc.) [Quest-teachers]". A mechanism for helping teachers in processing the data from the questionnaires and log files, as well as in automatically organizing the students in groups, is bound to overcome these difficulties.

\section{Summary and Conclusions}

This paper has presented a case study carried out in an introductory course of engineering education in which a Jigsaw CLFP with mobile and network technologies have been combined so as to generate a CSCBL scenario for facilitating students' transition from high school to university (in this case, UPF). There is evidence to support that the objectives of the course were achieved. One of the aims of the activity was to make students familiar with the structure of the campus and the services provided by university. The findings confirm that all students succeeded in answering the individual questionnaire about the campus, and that those who experienced the exploration with mobile phones, obtained slightly better marks, more precise and original descriptions in their presentations. Another objective was to make students familiar with the methodologies carried out at UPF which they will have to learn and use during their studies. The combination of activities and methodologies in the same experience enables the students to get a better understanding of the different methodologies that they will find along their engineering studies. Finally, the findings demonstrate that the CSCBL activity was very well accepted by both students and teachers. Whereas some technological and usability issues were raised by the participants, students preferred the CSCBL type of experience compared to others activities, and teachers highlighted the learning and motivational benefits provided by the experience. Moreover, during the experience, other students from Journalism, Advertisement and Translation 
and Interpretation degrees manifested their interest on the activity by asking whether they could participate. That was not appropriate because the contents of the experience were especially prepared with information relevant to engineering students in the context of the ICTI course (e. g. their laboratories, their secretariat...). Nevertheless, the activities, tag contents and their spatial distribution can be easily adapted to other degrees and contextualized in an introductory course included in other degree syllabus. The possibility of adapting the experience to other degrees shows the relevance of the activities and of the technological environment proposed to enhance first-year university students' introduction to their new educational context. Therefore, we can claim that the CSCBL experience presented, and the technological environment developed for its support, reported significant and motivational learning benefits to students. The results also show that this approach is an innovative mechanism for alleviating first-year students' transition from high School to university.

Another contribution of the study is the CSCBL approach itself. In particular, the experience presented is an example of how the workflow of the Jigsaw CLFP with an appropriate use of technology can be adapted for supporting and facilitating the orchestration of formal and informal collaborative activities occurring in different spatial locations. The technological environment consisting of a combination of mobile phones, NFC tags and software tools such as Moodle and Google Docs, allowed for integrating different activities into a unique learning setting. Mobile phones combined with NFC technologies allowed for capturing the activity of the students when visiting the campus, whereas Moodle and Google Docs were effectively used for structuring and guiding the activities in and out of university. Similar technologies such as GPS or Bluetooth might have been used in this scenario. However, the technological system should assure their integration in order to support all the activities included in the CSCBL scenario. 
The technological solution adopted in this study aims at being an example of how to benefit from good educational practices and novel technology, which can be extrapolated to other innovative collaborative blended learning scenarios. Altogether shows how network, computer technologies and learning techniques complement each other for the generation of new fruitful educational scenarios that open up new opportunities for learning through collaboration.

Case studies in different learning contexts are needed to further evaluate the suitability of the approach proposed. More experiences using mobile applications with NFC and other technologies, such as GPS, are planned. Currently, we are analyzing the results of a similar collaborative experience carried out with secondary school students for supporting assessment in situ. The limitations and problems reported in this case study have been taken into account for designing this activity and improving the technology for automating some aspects of the orchestration, such as functionalities for grouping students according to the expertise or visualizing the historic of the participants. The main results of this study and next experiences might lay the basis for a model to generalize the main factors that should be considered when orchestrating potentially effective computer supported collaborative blended learning experiences.

\section{Acknowledgements}

This work was supported in part by the Spanish Ministry of Science and Innovation in the Learn3 project TIN2008-05163/TSI and by the Madrid regional Government in the eMadrid project S2009/TIC-1650. The work of the author Ramirez-Gonzalez has been also supported by the SOLITE CYTED Program 508AC0341 and the Universidad del Cauca where he is a professor with a commission of Doctoral studies O.J. 118-2006. The authors also thank Sergio Sayago for his comments and revisions in final versions of this manuscript. 


\section{References}

Anderson-Rowland, M., Banks, D. L., Vanis, M.I., Matar, B., Chain, E. \& Zerby, D. M.. METS: A Collaboration to Assist Students Transitioning Into Engineering From The Community Colleges To The Unversity. $34^{\text {th }}$ ASEE/IEEE Frontiers in Education Conference, Savannah, GA, October 20-30; 2004.

Aronson, E., Blaney, N., Stephan, C., Sikes, J. \& Snapp, M. The jigsaw classroom. In Improving academic achievement: impact of psychological factors on education (pp. 213-224). London: Emerald Groups Pub Ltd; 2002.

BlueCove Project, May 2010. http://code.google.com/p/bluecove/. Accessed December 28, 2010.

Cook, J., Bradley, C., Holley, D., Smith, C. \& Haynes, R. Introducing blended mLearning solutions for higher education students, $5^{\text {th }}$ International Conference on Mobile Learning, MLearn’06, Alberta, USA, October 22-25; 2006.

Cook, J., Pachler, N. \& Bradley, C. Bridging the gap? Mobile phones at the interface between informal and formal learning. Journal of the Research Centre for Educational Technology. Special Issue on Learning While Mobile; 2008.

Courter, S.S. \& Anderson, K.J.B. First-year Students as Interviewers: Uncovering What It Means to Be an Engineer, $39^{\text {th }}$ ASEE/IEEE Frontiers in Education Conference, San Antonio, USA, October 18-21; 2009. pp. T1A(1-6).

Dillenbourg, P. Integrating technologies into educational ecosystems. Distance Education 2008; 29, 2(14), 127-140.

Dillenbourg, P. \& Fischer, F. (2007). Basics of Computer-Supported Collaborative Learning. Zeitschrift für Berufs- und Wirtschaftspadagogik 2008; 21, pp. 111-130.

Dougiamas, M. \& others. Moodle, http://www.moodle.org. Accessed December 28, 2010. 
European Higher Education Area (EHEA), http://ec.europa.eu/education/lifelong-learningpolicy/doc62_en.htm, $\quad$ http://ec.europa.eu/education/policies/educ/bologna/bologna.pdf. Accessed December 28, 2010.

Facer, K., Joiner, R., Stanton, D., Reid, J., Hull, R. \& Kirk, D. Savannah: mobile gaming and learning?. Journal of Computer Assisted Learning 2004, 20(6), pp. 399-409.

Frechtling, J., \& Sharp, L. User-friendly handbook for mixed method evaluations. In Frechtling, J., \& Sharp, L. (Eds.) Directorate for Education and Human Resources Division of Research, Evaluation and Communication NSF; 1997.

Gahan, C. \& Hannibal, M. Doing qualitative research using QSR NUD* IST. London: Sage Publications Ltd.

Google Docs, http://www.google.com/intl/en/press/annc/docsspreadsheets.html. Accessed December 28, 2010.

Guba, E.G. (1981). Criteria for assessing the trustworthiness of naturalistic inquiries. Educational Technology Research and Development 1998, 29, 2, pp. 75-91.

Haag, S. \& Collofello, J. Engineering Undergraduate Persistence and Contributing Factors. $38^{\text {th }}$ ASEE/IEEE Frontiers in Education Conference, Saratoga Springs, NY, October 22-25; 2008.

Hernández-Leo, D., Asensio-Pérez, J.I. \& Dimitriadis, Y. Computational Representation of Collaborative Learning Flow Patterns using IMS Learning Design. Journal of Educational Technology Society 2005, 8(4), pp. 75 - 89.

Hernández-Leo, D., Villasclaras-Fernández, E.D, Asensio-Pérez, J.I. \& Dimitriadis, Y. Generating CSCL Scripts: From a conceptual model of pattern languages to the design of real scripts. In Goodyear, P. \& Retalis, S. (Eds). E-learning Design Patterns Book, Newbury Park: Sage publications 2009, pp. 49-64. 
Hernández-Leo, D., Bote-Lorenzo, M., Asensio-Perez, J.I., Gomez-Sanchez, E., VillasclarasFernandez, E., Jorrin-Abellan, I. \& Dimitriadis, Y. Free-and Open-Source Software for a Course on Network Management: Authoring and Enactment of Scripts Based on Collaborative Learning Strategies. IEEE Transactions on Education 2007, 50(4), pp. 292-301.

Innovision Research \& Technology, http://www.innovision-group.com. Accessed December 28, 2010.

Manish, B. \& Shahram, M. RFID Field Guide: Deploying Radio Frequency Identification Systems. In Prentice Hall PTR. NJ: Upper Saddie River; 2005.

Martínez Monés, A., Dimitriadis, Y., Rubia Avi, B. , Gómez Sánchez, E., Garrachón, I. \& Marcos García, J.A. Studying social aspects of computer-supported collaboration with a mixed evaluation approach. Proceedings of the Int. Conference on Computer Support for Collaborative Learning (CSCL), Boulder, Colorado, USA, January 7-11, 2002, pp. 631-632.

Martínez-Monés, A., Gómez-Sánchez, E., Dimitriadis, Y., Jorrín-Abellán, I. M., Rubia-Avi, B. \& Vega-Gorgojo, G. Multiple case studies to enhance project-based learning in a computer architecture course. IEEE Transactions on Education 2005, 48(3), pp. 482-489.

Meeting the Campus 2009, http://193.145.50.210:8080/DocumenationJNCA/MeetingCampus2009-Web.html. Accessed December 28, 2010.

Moodle, http://moodle.org/?lang=en. Accessed December 28, 2010.

Müeller, S. Electronic mentoring as an example for the use of information and communications technology in engineering education. European Journal of Engineering Education 2004, 29(1), pp. 53-63.

N. Forum. NFC record type definition (rtd). Technical specification. NFC Forum, 2007. http://www.nfc-forum.org/specs/spec_list/\#rtds Accessed December 28, 2010. 
N. Forum. Text record type definition. Technical specification. NFC Forum, 2006. http://www.nfc-forum.org/specs/spec_list/\#rtds Accessed December 28, 2010.

N. Forum. Uri record type definition. Technical specification. NFC Forum, 2006. http://www.nfc-forum.org/specs/spec_list/\#rtds Accessed December 28, 2010.

N. Forum. Type 1 tag operation specification. Technical specification. NFC Forum, 2010. http://www.nfc-forum.org/specs/spec_list/\#tagtypes Accessed December 28, 2010.

N. Forum. Logical link control protocol. Technical specification. NFC Forum, 2009. http://www.nfc-forum.org/specs/spec_list/\#protts Accessed December 28, 2010.

Parker, J.D.A., Summerfeldt, L.J., Hogan, M.J. \& Majeski, S.A. Emotional intelligence and academic success: Examining the transition from high school to University. Personality and Individual Differences 2004, 36(1), pp. 163-172.

Roschelle, J. \& Pea, R. A walk in the wild side: How wireless handhelds may change CSCL. Computer Support for Collaborative Learning: Foundations for a CSCL community, Boulder, Colorado, 2002, pp. 51-60.

Schwabe, G. \& Goth, C. Mobile learning with a mobile game: design and motivational effects. Journal of Computer Assisted Learning 2005, 21(3), pp. 204-216.

Sharples, M., Lonsdale, P., Meek, J., Rudman, P. \& Vavoula, G. An evaluation of MyArtSpace: A mobile learning service for school museum trips, $6^{\text {th }}$ International Conference on Mobile Learning, Melbourne, Australia, October 16-19; 2007.

Sticklen, J., Urban-Lurain, M. \& Briedis, D. Engagement of Millennial Students Using Webbased Screen Movies to Replace Traditional Lecture in Lecture/Lab Courses. $39^{\text {th }}$ ASEE/IEEE Frontiers in Education Conference, San Antonio, TX, USA, October 18-21, 2009, M3C(1-5).

Sweeney, P.J. RFID for Dummies, Inc. Hoboken, NJ: Wiley Publishing; 2005.

UPF Webpage, http://www.upf.edu. Accessed December 28, 2010. 
West, L.L. Effective strategies for dropout prevention of at-risk youth. In West, L.L, (Eds.). Aspen: Gaithersburg, MD; 1991002E 